\title{
A PRESTAÇÃO DE SERVIÇOS NOS ESTADOS DO MERCOSUL
}

\section{Renata Cristina de Oliveira Alencar Silva*}

SUMÁRIO: 1. Introdução. 2. A Liberdade de Circulaçẫo e de Estabelecimento. 3. A Prestação de Serviços. 4. A Prestação de Serviços nos Estados do MERCOSUL. 5. A Prestação de Serviços nos Estados Associados do MERCOSUL. 6. A LivTe Circulaçã̃o de Serviços no Protocolo de Montevidéu. 7. Conclusäo. 8. Bibliografia.

SUMMARY: Introduction. 2. The Liberty of Circulation and of Establishment. 3. The Installment of Service. 4. The Installment of Service in the States of the MERCOSUL. 5. The Installment of Service in the States Associated of the MERCOSUL. 6. the Free Citculation of Service in the Protocol of Montevideo. 7. Conclusion. 8. Bibliography

RESUMO: Uma das bases para o estabelecimento de um mercado comum entre parte dos paises da América do Sul está pautada na liberdade de circulação, seja de bens, seja de fatores produtivos. Justifica-se, assim, o presente trabalho, que estuda a prestação de serviços nos Estados do Mercado Comum do Sul (MERCOSUL), analisando as principais similitudes e diferenças na legislação de cada Estado-Parte integrante do bloco.

ABSTRACT: One of the bases for the establishment of a common market between countries from the South America is lined in the liberty of circulation of property or productive factors. The present work, that studies the installment of service in the States of the Common Market of the South (MERCOSUL), analyzing the similitude and differences in the legislation of each member of the economical block.

RESUMEN: Una de las bases pata el establecimiento de un mercado común entre los paises de la Sudamérica se forra en la libertad de la circulación de

"Mestre en Direito Negocial pela Universidade Estadual de Londrina PR. Professora da Faculdade Panaense - FACCAR. Adwogada. E-mail: renatadvobolcom.bo 
la propiedad o de los factores productivos. El trabajo presente, estudia el del servicio en los Estados del Mercado Común del Sur (MERCOSUR), las semelhanças y las diferencias principales en la legislación de cada miembro del bloque económico.

PALAVRAS-CHAVES: Serviços. Prestação de serviços. MERCOSUL. Protocolo de Montevidéu. Livre circulação.

KEY-WORDS: Services. Service Installmente. MERCOSUL. Montevidéu Agreement, People Mobility.

PALABRAS-LLAVES: Servicios. Prestacione de Servicios. MERCOSUR Protocolo de Montevideo. Circulacion de Personas.

\section{Introdução}

A Declaração Universal dos Direitos do Homem estabelece, em seu art. 13 , o direito de livre locomoção das pessoas, proclamando que todo homem tem direito à liberdade de locomoção e residência dentro das fronteira de cada Estado. Todo homem tem direito de deixar qualquer país, inclusive o próprio, e a este regressar.

Isso significa que o homem tem o direito de circular livremente dentro e fora do território do Estado ao qual pertence, dele saindo e podendo retornar, quando e quanto desejar.

Nesse mesmo sentido, o Tratado de Assunção estabelece a liberdade de circulação de bens, serviços e fatores produtivos entre os Estados-Partes do MERCOSUL como fundamento do mercado comum ${ }^{2}$. Além disso, o artigo $1^{a}$ do Tratado de Assunção estabelece a coordenação de políticas macroeconômicas e setoriais entre os Estados-Partes para a implementação da liberdade de circulação e, consequentemente, de estabelecimento.

Uma das bases para o estabelecimento de um mercado comum entre parte dos países da América do Sul está pautada na liberdade de circulação, seja de bens, seja de fatores produtivos. Justifica-se, assim, o presente trabalho, que estuda a prestação de serviços nos Estados do Mercado Comum do Sul (MERCOSUL), analisando as principais similitudes e diferenças na legislação de cada Estado-Parte integrante do bloco.

\footnotetext{
Declaraçäo Universal dos Direitos do Homem. Disponivel em http//wwwunhchr.ch/udhr/Lng/ por.htm. Acessado em $09 / 09 / 2002$.

Tratado de Assunção, Art. 1‥ Disponthel em http//www.mercosurorguy/ paginabienvenidaportugues.hem. Acessado $\mathrm{em} \mathrm{17/07/2002.}$ 


\section{A Liberdade de Circulação e de Estabelecimento}

A livre circulação de serviços tem, como pressuposto, a livre circulação de pessoas ${ }^{3}$. É evidente que para que haja a liberdade de prestação de serviços, as pessoas, necessariamente, têm que deter a liberdade de circulação no âmbito dos Estados-Partes do MERCOSUL.

Ao mencionar a liberdade de circulação dos fatores de produção, o Tratado de Assunção estabelece que o homem terá liberdade para deslocar-se intrabloco sem qualquer tipo de restrição, podendo, inclusive, instalar-se em outro país e nele exercer atividade, transferindo seus ganhos para outros países do bloco sem custo adicional ${ }^{4}$.

Contudo, nãoestabelece normas específicas para a livre circulação de pessoas, bens ou capitais, constituindose em uma norma de conteúdo programático, com a finalidade de fornecer bases e prinćpios para a construção de um mercado comum5.

Ao MERCOSUL, que compreende a formação de um Mercado Comum e que requer a livre circulação de todos os fatores de produção, no dizer de Roberto Norris $^{6}$, necessárias são as cinco liberdades básicas para a formação de um mercado comum: a livre circulação de pessoas e serviços, a livre circulação de bens, a livre circulação de capitais, de concorrência e a liberdade de estabelecimento.

Entende-se por liberdade de estabelecimento a eliminação de qualquer discriminação em razão da nacionalidade e que esta deva ser alcançada mediante atendimento ao princípio do equilíbrio econômico entre os Estados-Partes. A liberdade de estabelecimento constitui-se no direito que toda pessoa tem de se estabelecer materialmente em qualquer um dos EstadosPartes do MERCOSUL e desenvolver uma atividade econômica independente e não assalariada por um espaço de tempo indeterminado

VEERA, D. C. O Fxercício da advocacia no Mercosul frente à live circulaşăo de serviços e trabalhadores. Im: RODRIGUES, H. W. (org). Soluçâ de Controversias no Mercosul Porto Alegre: Livara do Advogado, 1997, p. 116. + LIPOVETZKY, J. C. LIPOVETZKY, D. A. MERCOSUL estratégias pela integraçäo: Mercado Comum do ou Zona de Livre Comércio? Analise e perspectivas do Tratado de Assunçăo. Säo Paulo: LTr, p. 84.

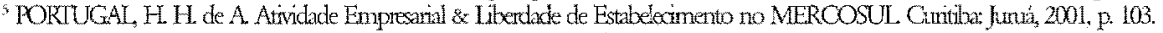
"NORRIS, R Contratos Coletivos Supranacionais de Trabalho e a Internacionalizaça das Relações Laborais no MERCOSUL. São Paulo: LTr, 1998. p.39 e s.

Há autores que ignoram a liberdade de concorrencia, defendendo a existência de somente quatro liberdades. A justificativa está no fato de o Tratado de Assunção não estabelecer de forma expressa a liberdade de concortencia, como o faz com as demais liberdades, em seu attigo $1^{\mathrm{a}}$. Considerando-se o disposto em referido artigo do Tratado, a liberdade de concorrência é decorrencia das demais liberdades, pois a coordenaçâo de políticas macroeconômicas e setoriais entre os Estados Partes tem como objetivo assegurar condiçöes adequadas de concorrência entre os Estados-Partes. Nesse sentido MORENO, A. S. Simetrias y assimetrias entre Europa y America Latina en la integracion. La cuestion migratoria. In: CALDANI, M. A. C. Del MERCOSUR: Aduana, Jurisdicion, Informática y Relaciones Intercomunitarias. Buenos Aires: Ediciones Ciudad Argentina, 1996, p. 350; LINAAN NOGUERAS, D. I. El Mercado Interior: las cuatro liberdades. In: RINOLDI LADMANN, E (coord). Mercosur y Comunidad Europea. Buenos Aires: Ediciones Ciudad Argentina, 1995, p. 89-93.

* En 25 de julho de 1991, a Corte de Justiça Europeca definiu a noção de cstabelecimento, conforme o artigo 52 do Tratado de Roma, afirmando que ela comporta o exercicio efetivo de uma atividade econômica por meio de uma instalação estável em outro Estado membro por uma duraçăo inderterminada. 
Em relação à empresa, liberdade de estabelecimento não é sinônimo de inobservância das normas em vigor no país de estabelecimento. Significa dizer que a empresa oriunda de outro Estado estará sujeita às mesmas regras impostas às empresas nacionais, sendo vedada a prática de condições abusivas?

\section{A Prestação de Serviços}

A prestação de serviços no âmbito internacional constitui-se no deslocamento de bens, capital, pessoas e informações através das fronteiras de um país, para receber ou oferecer serviços ${ }^{10}$.

Segundo as palavras de Araminta Mercadante ${ }^{11}$, o comércio internacional de serviços é o conjunto de atividades econômicas em que há movimento transfronteira de invisiveis ou de pessoas que os executam, sem envolver mercadorias. Ou seja, deve haver o deslocamento além das fronteiras de um Estado de bens incorpóreos, através ou não de pessoas que os desloque.

A dificuldade de conceituação dos serviços ${ }^{12}$ foi superada pela classificação das atividades assim consideradas ou, ainda, pela divisão dos serviços em categorias ${ }^{13}$.

Dessa forma, a liberdade de prestação de serviços está intimamente ligada à liberdade de circulação de pessoas, sejam físicas ou jurídicas.

Tal liberdade consiste na possibilidade de pessoas fisicas ou jurídicas, nacionais de um Estado-Parte prestarem seus serviços livremente nos demais Estados, inclusive fixando residência, mediante igualdade de condições com os nacionais.

Há quatro modalidades ${ }^{14}$ de prestação de serviços. A denominada de comércio transfronteiriço, ocorre com o fornecimento de um serviço do território de um Estado-Parte ao território de outro Estado-Parte, sem que haja deslocamento do prestador ou do adquirente. Ou seja, o serviço cruza as fronteiras e não as partes envolvidas ${ }^{15}$.

Outra forma de prestação de serviços acontece com o deslocamento do cliente adquirente do serviço até o território do Estado-Parte do fornecedor ${ }^{17}$.

\footnotetext{
"TAMAMES, R. Ya Unión Europea. Madrid: Alianza Editorial, 1994. p.185.

UNCTAD. Infome sobre comércio e desenvolvimento, apud PRONER, C. Comércio de Serviços. In BARRAL. W. (org.). O Brasil e a OMG, $2^{\circ}$ ed, Curitba: Juruá, 2002, p. 67.

"MERCADANTE, A.A. Acordo Geral sobre o Comércio de Servicos: aspectos juridicos. In: CASELLA, P. B.; MERCADANTE, A de A. (coord.); Guerra comercial ou integração mundial pelo conzércio? A OMC e o Brasil. São Paulo: LTr, 1998, p. 419.

${ }^{12}$ Note-se que no âmbito da Organizaçăo Mundial do Comércio, das normas da Uniäo Europèia e do MERCOSUL, não há uma definição de serviços, limitandose tais normas em classiffcalos em modalidades. ${ }^{13}$ PRONER, C. Comério de Serviços. In; BARRAL W. (org). O Brasil e a OMC, 2 ed, Curiuba Juruá, 2002, p. 67.

Hi General Agrement on Trade in Service (GATS), att. I, 2. Disponivel en wwwwtoong. Acessado em 02/09/2002.

15. Os serviços de telecomunicaçöes e de transferências bancáras, entre outros, săo exemplos dessa modalidade.

"HARGAIN, D. Marco Junídico del Comercio Internacional de Servicios. In: Revista de Derecho del Mercosur, n." 4, Buenos Aires, 2001, p. 43.

${ }_{17}$ Tal como ocorre em viagens turísticas e cursos de línguas no exterior.
} 
A prestação de serviços também pode ocorrer com o deslocamento temporário do prestador de serviços ao território do Estado-Parte do adquirente. Vale salientar que o deslocamento deve ser necessariamente temporário, uma vez que o Anexo do Acordo Geral sobre Serviços (GATS) sobre circulação de pessoas não se refere aos casos de deslocamento permanente de pessoas, sejam físicas ou jurídicas ${ }^{18}$.

Quando acontece o estabelecimento do fornecedor de serviços, oriundo de um Estado-Parte, no território do Estado-Parte do adquirente, através de filiais ou sucursais, também considera-se como modalidade de prestação de serviços ${ }^{19}$.

No âmbito da legislação interna dos Estados-partes do MERCOSUL, a forma de disciplinar a matéria possui peculiaridades. Não há legislação especifica sobre o assunto, guardando similitudes umas com as outras.

\section{A Prestação de Serviços no MERCOSUL}

A prestação de serviços, em que pese estar disciplina no Código Civil de todos os Estados-partes do MERCOSUL, possui algumas peculiaridades.

Na Argentina, a prestação de serviços é tratada pelo Código Civil de 1869 sob a denominação locação de serviços. Os dispositivos relativos ao tema estão no Título Locação, Capítulo VIII, artigos 1623 a 1647 bis. Nesse mesmo capítulo está inserido o tema locação de obras, que no direito brasileiro é conhecido com empreitada, a partir do artigo 1629.

Verifica-se, pelo disposto no art. 1623 que, para a legislação civil argentina, a locação de serviços constitui-se em um contrato consensual, ainda que o serviço a ser prestado fosse a entrega de uma coisa por uma das partes ${ }^{20}$.

Ainda, segundo referido artigo, a locação de serviços tem lugar quando uma das partes se obriga a prestar um serviço e a outra parte obrigase a pagar por esse serviço certa quantia em dinheiro.

Sempre que alguém prestar um serviço a outrem, que decorra de sua profissão ou modo de viver, poderá solicitar o valor correspondente, mesmo que não tenha

\footnotetext{
${ }^{13}$ Como exemplo, citar-se a prestação de serviços por técnicos especializados que prestam assistência técrica a enpressas cstrangeiras.

19 Exemplo dessa modalidade são os bancos e as empresas seguradoras, que se instalam em vários outros paises para prestar serviços aos nacionais destes.

20) Código Civil da Argentina, art. 1623: Art.1623.- La locación de servicios es un contrato consensual, aunque el servicio hubiese de ser hecho en cosa que una de las partes debe entregar. Tiene lugar cuando una de las partes se obligare a prestat un servicio, y la otra a pagarle por ese servicio un precio en dinero. Los efectos de este contrato setan juzgados por las disposiciones de este Codigo sobre las "Obligaciones de hacer".
} 
havido um prévio ajuste. Nesse caso, o preço será determinado por arbitramento. $\dot{E}$ o que se extrai do disposto no art. $1627^{21}$ do Código Civil Argentino.

Uma peculiaridade em referida legislação é o que está disposto no Art. $1626^{22}$ que não permite ao tomador dos serviços a reclamação pelo serviço, tampouco de exigir a devolução do valor pago, caso sejam realizados serviços impossíveis, ilícitos ou imorais. Isso porque conclui-se a possibilidade de contratação de um serviço impossível, ilícito e imoral.

O Código Civil Brasileiro ${ }^{23}$ estabelece no Título VI, Das Várias Espécies de Contrato, Capítulo VII, intitulado Da Prestação de Serviços, que a prestação de serviços, que não estiver sujeita às leis trabalhistas ou à lei especial, será regida pelas disposições da lei civil.

No Código Civil Brasileiro de 1916, assim como nos demais Estadospartes do MERCOSUL, à exceção do Paraguai, os contratos de prestação de serviços eram chamados de Locação de Serviços, denominação considerada equivocada por Jorge Lages Salomo ${ }^{24}$, haja vista que na locação o bem locado retorna ao seu dono, enquanto que, na prestação de serviços, o serviço prestado não é passível de devolução.

Além disso, essa denominação para Pontes de Miranda ${ }^{25}$ e Clóvis Bevilaqua26, tem origem no trabalho escravo, pois tanto em Roma como na Grécia, o serviço braçal e rudimentar era considerado humilhante e desonroso, fazendo do escravo uma mercadoria, passível de aluguel, compra e transporte. Os serviços braçais prestados por homens livres também eram equiparados aos prestados pelos escravos, ou seja, eram considerados mercadorias.

Até o surgimento da legislação trabalhista, as disposições do Código Civil também regulavam as atividades de trabalhadores assalariados. Contudo, o conceito de prestação de serviços deve estar desvinculado das atividades realizadas mediante subordinação hierárquica e dotadas do caráter de continuidade ${ }^{27}$.

\footnotetext{
st Código Civil da República Argentina, art 1627: El que hiciere algún trabajo, o prestare algún servicio a otro, puede demandar el precio, aunque ningún precio se hubiese ajustado, siempre que tal servicio o trabajo sea de su profesión o modo de vivir. En tal caso, entiéndese que austaron el precio de costumbre para ser determinado por ábittos.

22 Código Civil da República Argentina, art 1626: Si la locación urviese por objeto prestaciones de servicios imposibles, ilicitos o inmorales, aquel a quien tales servicios fuesen prestados, no tendrá derecho para demandar a la otra parte por la prestación de esos servicios, ni para exigir la restitución del precio que hubiese pagado.

${ }^{23}$ Lei n. 10.406 , de 10/01/02, publicada no Diário Oficial da União em 11 de janeiro de 2002.

2. SALOMO, J. L. Aspectos dos Contratos de Prestaçäo de Serviços. São Paulo: Juarez de Oliveira, 1999, p. 1.

2 PONTES DE MIRANDA, F. C. Tratado de Díreito Privado, v, 47, São Paulo: Revista dos Tribunais, 1984, p. 7.

26. BEVILAOUA, C. Teoria das Obrigações, edição histórica, Rio de Janeiro: Editora Rio, 1977, p. 342.

${ }^{27}$ Segundo o art. $3^{*}$ da Consolidaçâ das Leis do Trabalho, consideràse empregado toda pessoa fisica que prestar serviços de natureza näo eventual a empregador, sob a dependência deste e mediante salário. 
No âmbito do Direito Civil, a prestação de serviços constitui-se na realização de uma atividade com liberdade técnica, sem traço de subordinação hierárquica e de maneira eventual, melhor dizendo, que não seja constantemente necessária e que não seja habitualmente prestada para o mesmo contratante ${ }^{28}$.

O Código Civil Brasileiro em vigor, assim como o anterior, define a prestação de serviços como sendo toda espécie de serviço ou trabalho lícito, material ou imaterial ${ }^{29}$, ao contrário da legislação argentina. Sendo assim, o tema é vasto, não se limitando à locação e à empreitada, como a legislação o tratava ${ }^{30}$.

A inovação da legislação brasileira está no fato da legislação admitir a forma de arbitramento como solução de eventuais controvérsias sobre o preço ajustado. A solução seria apresentada por árbitros escolhidos pelas partes e sem a participação do Poder Judiciário ${ }^{31}$. É feita uma avaliação com base nos fatos e circunstâncias aplicáveis ao caso em análise.

A crítica que se faz quanto à matéria disciplinada pelo Novo Código é quanto à utilização equivocada de expressões como salário e despedida sem justa causa ${ }^{32}$, próprias do Direito do Trabalho.

Conforme dito, a prestação de serviços que não for regulada pela legislação trabalhista, ou seja, aquela que for desenvolvida sem vínculo empregatício, será regida pela legislação civil. Por esse motivo, o uso de expressões próprias da legislação trabalhista pode gerar dúvidas ao intérprete da lei.

O ideal seria a substituição da expressão salário por preço ou retribuição, assim como a expressão justa causa poderia ser substituída por denúncia imotivada ${ }^{33}$.

Outra novidade está por conta do artigo 606 do Código Civil Brasileiro, que prevê a necessidade de remunerar o prestador de serviço, ainda que esse não possua a habilitação técnica correspondente, caso ele tenha agido de boa-fé em beneficio da outra parte ${ }^{34}$

\footnotetext{
* SALOMO I. L. Aspectos dos Contratos de Prestação de Serviços. São Paulo: Juarez de Oliveira, 1999, p. 5.

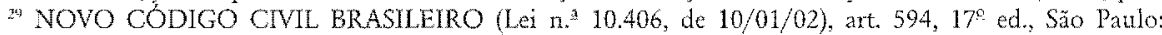

Saraiva, 2002, p. 1145.

". ALVES, J. F, In: FIUZA, R. (coord.). NOVO CÓDIGO CIVIL COMENTADO. $1^{\circ}$ ed., $8^{\circ}$ tiragem. São Paulo: Saraiva, 2002 , p. 531 .

3 DE PLÁCIDO E SILVA. Vóabulo Juridico. Rio de Janeiro: Forense, 1975, v. 1.

${ }^{32}$ Nesse sentido, vide artigos 599,602 e 603 do Código Civil.

3. SALOMO, J. L. Contratos de Prestação de Serviços: manual prático e teórico. São Paulo: Juarez de Oliveira, 2001 , p. 26.

${ }^{4}$ PEDUZZZ, M. C. I A prestagäo de servicos. In: FRANCIULU NETTO, D; MENDES, G. F; MARTLNS FILHO, I. G. da. O Novo Cótigo Civil estudos en homenagen ao prof. Miguel Reale Săo Paulo: LT, 2003, p.559.
} 
Dessa forma, remunera-se o serviço prestado, sem que haja vantagem ao prestador, coibindo, ao mesmo tempo, o exercício ilegal de uma atividade.

A interpretação literal do artigo 605 do Código Civil transmite o entendimento de que as normas estabelecidas pela legislação brasileira aplicam-se somente às pessoas físicas, dado o caráter personalíssimo do contrato $^{35}$. Ao contrário, assegura-se que a parte contratante, seja pessoa física ou jurídica, será a responsável pela execução do contrato, até porque a legislação não restringe a prestação de serviços por pessoa jurídica.

O Código Civil do Paraguai regula o contrato de serviços a partir do Art. 845. Constitui-se em um Código avançado se comparado aos demais Códigos dos Estados do MERCOSUL, posto que o contrato de serviços está inserido em tópico distinto da locação e da empreitada, nos mesmos moldes da legislação civil brasileira.

O caráter personalíssimo da obrigação é identificado no Art. $846^{36}$. Referido artigo obriga o prestador de serviços a prestá-lo pessoalmente, salvo disposição em contrário. Ou seja, salvo se o tomador do serviço concordar.

Um outro dispositivo que merece atenção é o art. $850^{37}$, que dispensa a denúncia do contrato de prestação de serviços, quando o contrato for assinado por prazo determinado ou quando sua duração resultar da finalidade pela qual o serviço foi proposto. Referido dispositivo aceita exceção, ou seja, permite que as partes estabeleçam regras em sentido contrário.

Caso não haja prazo estipulado no contrato, é permitido às partes rescindi-lo, mediante aviso à outra parte, com antecedência mínima de trinta dias.

Merece destaque a expressão denúncia, utilizada nesse artigo para indicar a rescisão do contrato, tal como mencionado quando do estudo da legislação civil brasileira ${ }^{38}$.

A legislação civil uruguaia dispõe sobre a locação de serviços segundo no Capítulo II, Do Arrendamento de Obras, inserido no Título IV, do Arrendamento, por sua vez integrante da Segunda Parte do Livro Quarto, intitulado Das Obrigações.

\footnotetext{
PEDUZZI, M. C. I. A prestação de serviços. In: FRANCIULII NETTO, D; MENDES, G. F; MARTINS FILHO, I. $G$. da. $O$ Novo Codigo Civil: estudos em homenagem ao prof. Miguel Reale. Säo Pado: XTr, 2003 , p. 539.

3. Código Civil Paraguaio, art.846: El obligado a la prestación de un servicio debe ejecutarlo personalmente y esta prestación es incesible, salvo convención en contratio.

si. Código Civil laraguaio, art 850 : Salvo convención en contrario, el contrato de servicios hecho por un plazo determinado, o crya duración resulta del fin para el cual el servicio fue prometido, termina a la expiración del plazo previsto, sin que sea menester su denuncia. Si no se hubiere fijado plazo, cualquiera de las partes podrá dar por terminado el contrato, dando aviso a la otra por lo menos con treinta dias de anticipación.

SALOMO, I. L. Aspectos dos contratos de prestação de serviços. São Paulo: Juarez de Oliveira, 1999. 
De maneira específica, somente os artigos 1831 a 1839 tratam do tema locação de serviços. Os demais artigos tratam da locação de obra que, conforme dito, corresponde ao contrato de empreitada brasileiro. Salienta-se que o Art. 1855 prevê que os serviços relativos a transportes de pessoas ou coisas serão regulados pela legislação comercial.

Segundo o Código, dá-se o arrendamento de obras quando uma das partes prestar serviços à outra mediante um preço em dinheiro ${ }^{39}$. Esse dispositivo encontra semelhança com o disposto na legislação argentina e paraguaia, conforme citado nos itens anteriores.

Semelhante ao direito brasileiro, o artigo 1833 possibilita a contratação, através dessa modalidade de contrato, de toda espécie de serviço ou trabatho, material ou imaterial, mecânico ou liberal, ainda que o valor pago por ele tenha o nome de honorários ou direitos ${ }^{40}$. Salienta-se ainda que esse artigo se aplica também aos serviços de advogados ou procuradores quando esses atuarem sem autorização das partes.

Prova da influência do direito argentino, o artigo $1834^{41}$ da legislação uruguaia é muito semelhante ao disposto nos artigos 1627 e 1628 daquela lei civil. Dispõe que quando alguém prestar um serviço a outrem, em conseqüência de sua profissão ou modo de viver, poderá cobrar o respectivo valor, mesmo sem prévio ajuste. A determinação do valor, como no direito argentino, ocorrerá por arbitramento.

\section{A Prestação de Serviços nos Estados Associados do MERCOSUL}

\section{É Importante analisar a legislação dos Estados Associados ao MERCOSUL} no que tange à prestação de serviços. Esses Estados, em que pese não terem aderido integralmente ao MERCOSUL, fazem parte de alguns acordos comerciais. É uma adesão gradativa, que pode ou não ser implementada.

\footnotetext{
3* Codigo Civil Uruguaio, art. 1831: Habra arrendamiento de obras cuando una de las partes se hubiere obligado a prestar un servicio y la otra a pagarle por ese servicio un precio en dinero.

to Salvo se o contrato for de representação ou mandato. Código Civil do Uruguai, art. 1833: Toda especie de servicio o trabajo material o inmaterial, mecánico o liberal puede ser objeto de este contrato Aunque la retribución del servicio o trabajo tenga el nombre de honorarios o derechos, el contrato será arendamiento de obras y no mandato, si no colocare a quieta presta el servicio, respecto de tercero, como representante o mandatario de la persona a quien se hace el servicio. En la disposicion de este artículo están comprendidos los servicios profesionales de los abogados y aun de los procuradores, cuando funcionaten sin poder de las partes.

4i Código Civil do Uruguai, art. 1834: El que hiciere algún trabajo o prestare algún servicio a otro puede demandar el precio, aunque ningún precio o retribucion se hubiese ajustado, siempre que el tal servicio o trabajo fuese de su profesión o modo de vivir honesto. En este caso se presumirá que los interesados ajustaron el precio de costumbre para ser deterninado judicialmente, si hubiere duda. Si el servicio o trabajo, aunque honesto, no fuere relativo a la profesion o modo de vivir del que lo hizos solo tendrá lugar lo dispuesto en el inciso anterior cuando, por las circunstancias, no se presuniere la intención de beneficiar a la persona a quien el servicio se hacia. Esta tntención se presume si el servicio no fue solicitado o si el que lo prestó habitaba en casa de la otra parte. En los casos de este artículo, si ha habido ajuste sobre el precio o retribución, lo pactado se cumplirá, siendo entre personas capaces y no probándose que intervino fuerza, etror, dolo o fraude.
} 
Para a implementação do comércio regional entre esses países, especialmente o de serviços, é essencial conhecer a forma com que a matéria é disciplinada no âmbito interno, como maneira de prever e evitar os possíveis conflitos existentes.

O Chile faz parte do Mercado Comum do Sul como Estado Associado.

A legislação chilena sobre a prestação de serviços também está disciplinada no Código Civil, nos artigos 1915 e seguintes.

Contrariando a tendência mundial de respeito à dignidade da pessoa humana, o Código Civil do Chile prevê o contrato de arrendamento de empregados domésticos. Isso porque somente as coisas são consideradas objeto de locação ${ }^{42}$. Quanto às pessoas, seus serviços é que podem ser objeto de locação, e não elas próprias.

Da mesma forma que o Chile, a Bolivia faz parte do MERCOSUL como Estado Associado.

O tema prestação de serviços está regulado pelo Código Civil, artigos 685 a 749 do Terceiro Livro, intitulado Das Obrigações, Título II, Dos contratos em particular.

Ao contrário dos demais Estados vistos anteriormente, o contrato de prestação de serviços é um contrato de obra, onde o contratante assume a responsabilidade pela realização de um trabalho prometido em troca de retribuição ${ }^{43}$, sendo que o objeto desse contrato pode ser a prestação de um serviço.

Em 25/08/2003, o Peru assinou um acordo de livre comércio com o MERCOSUL. A conseqüência desse acordo é a participação do Peru, a exemplo do Chile e da Bolívia, como Estado Associado do Mercado Comum do Sul e faz parte da estratégia de priorizar a integração da América do Sul.

Nesse acordo, estão previstas uma série de particularidades, diante da fragilidade da economia peruana, como a abertura gradativa do mercado, bem como o acesso rápido dos produtos peruanos aos mercados brasileiros e argentinos. Com relação ao prazo para acesso aos mercados bolivianos e paraguaios, esse será mais longo e gradativo. Serão permitidas salvaguardas aos produtos do Peru na área agrícola, caso necessárias para proteger o mercado nacional.

Por enquanto, as relações comerciais concentram-se no comércio de bens. Contudo, um dos assuntos em discussão na reunião ministerial por ocasião da assinatura do acordo foi a construção de rodovias e aproveitamento de

\footnotetext{
12 LOPEZ, T. A. Da prestação de serviço. In: AZEVEDO, A. J. de (coord.). Comentários ao Código Civil: parte especial; das vírias especies de contrato, vol. 7. Säo Paulo: Sararva, 2003, p. 189.

73 CODIGO CNIL DA BOLIVIA, Ant, 732.- (NOCION). I. Por el contrato de obra el empresario o contratista asume, por si solo o bajo su dirección e independientemente, la realización del trabajo prometido a cambio de una tetribución convenida. II. El objeto de este contrato puede ser la reparación o transformación de una cosa, cualquier otro resultado de trabajo o la prestación de servicios. 
hidrovias para permitir o escoamento da produção agrícola e industrial brasileira, principalmente da regiāo amazônica, através da construção e concessão de 960 quilômetros de rodovias por 25 anos.

Seguindo a tendência dos demais países do Cone Sul, o Peru também tem suas normas sobre prestação de serviços reguladas pelo Código Civil. A denominação utilizada é a da locação de serviços, nos mesmos moldes da legislação argentina e uruguaia.

A semelhança que guarda com a legislação brasileira é a do pagamento acontecer somente com o término do serviço, salvo por acordo entre as partes. Além disso, também estabelece, como no Código Civil Brasileiro, a prestação de serviços materiais e imateriais, sem subordinação ${ }^{44}$. No que diz respeito à rescisão, limita-se em prevêtla somente em caso de morte do prestador, sendo que o prazo máximo do contrato é de seis anos.

\section{A Livre Circulação de Serviços no Protocolo de Montevidéu}

Conforme dito, o artigo $1^{\text {a }}$ do Tratado de Assunção dispõe que o MERCOSUL implica, dentre outros compromissos, na livre circulação de serviços entre os países que o integram.

Para tanto, o Conselho do Mercado Comum, diante da necessidade de estabelecer princípios e disciplinas para promover o livre comércio de serviços entre os países integrantes do MERCOSUL, aprovou, por meio da Decisão 13/1997, o Protocolo de Montevidéu ${ }^{45}$ sobre o Comércio de Serviços do MERCOSUL.

Esse Protocolo contribuiu para diminuir as assimetrias, aproximando as legislações dos Estados-Partes em matéria de prestação de serviços. O objetivo é estabelecer o equilíbrio entre os Estados-Partes para que a integração não aconteça com a prevalência de um ou mais Estados em detrimento de um ou de outros.

Esse equilíbrio é alcançado através de programas de eliminação de barreiras tarifárias e não tarifárias, garantindo condições apropriadas de concorrência de produtos e serviços entre os países. Oferece, tambén, garantias compensatórias aos Estados-Partes, defendendo a integridade do bloco econômico ${ }^{46}$.

\footnotetext{
4 CODIGO CIVLL DO PERU, Artículo 1764.- Por la locación de servicios el locador se obliga, sin estar subordinado al comitente, a prestarle sus servicios por cierto tiempo o para un trabajo determinado, a cambio de una retribución. Articulo 1765. Pueden ser matetia del contrato toda clase de servicios materiales e intelectuales. 45 Ratifacado pelo Congresso Nacional Brasileiro através do Decreto Legislativo 335, de 24/07/2003, publicado no DOU em 25/07/2003. Contudo, para que seja incorporado ao Ordenamento Jurídico Brasileiro é necessário que ele esteja vigorando entre os países do MERCOSUL. Até agrora, somente a Argentina o ratificou, nâo sendo possível prever quando o processo estará conciúcio.

* REVISTA DO MERCOSUL apud PORTUGAL, H. H. de A. Atividade Empresarial \& Liberdade de Estabelecimento no MERCOSUL. Curitibas Juruá, 2001, p. 108
} 
O Protocolo de Montevidéu sobre Comércio de Serviços, assinado em 15 de dezembro de 1997, tem por finalidade eliminar as restriçōes ao livre trânsito de serviços dos países do MERCOSUL, que também são membros da Organização Mundial do Comércio (OMC). É baseado nas normas do General Agreement on Trade in Service (GATS), sendo que, para Daniel Hargain ${ }^{47}$, nada mais é do que uma cópia do Acordo Geral sobre Serviços.

Tendo em vista a ausência de um sistema positivado de prevalência supranacional, coube-lhe o papel de traçar regras que possibilitem e regulamentem tal atividade.

Uma crítica que se pode tecer ao Protocolo de Montevidéu direcionase exatamente quanto à definição dos serviços que tenta regular. Em seu artigo II, item 2 , preceitua que:

Para fins do presente Protocolo, o comércio de serviços é definido como: a) do território de um Estado Parte ao território de qualquer outro Estado Parte; b) no território de um Estado Parte a um consumidor de serviços de qualquer outro Estado Parte; c) por um prestador de serviços de um Estado Parte mediante a presença comercial no território de qualquer outro Estado Parte; d) por um prestador de serviços de um Estado Parte mediante presença de pessoas físicas de um Estado Parte no território de qualquer outro Estado Parte ${ }^{48}$.

Dessa forma, são estabelecidas as quatro modalidades de prestação de serviços. Seguindo o modelo do GATS, o Protocolo de Montevidéu, estabelece como forma de comércio de serviços aquele prestado do território de um Estado-Parte ao território de qualquer outro Estado-Parte, também conhecido como comércio transfronteiriço, onde não há o deslocamento de qualquer das partes envolvidas na transação.

A prestação de serviços no território de um Estado-Parte to consumidor de serviços de outro Estado-Parte, ou seja, com o deslocamento do adquirente e não do prestador do serviço também é modalidade prevista.

O Protocolo de Montevidéu estabelece ainda a prestação de serviços de um Estado-Parte mediante a presença comercial no território de outro Estado-Parte. Essa presença comercial pode acontecer através de pessoas jurídicas constituídas no território do outro Estado-Parte.

Finalmente, a prestação de serviço que acontece através da presença

\footnotetext{
${ }^{77}$ HARGAIN, D. Marco Juridico del Comercio Intemacional de Servicios. In: Revista de Derecho del Mercosur, n.' 4, Buenos Aires, 2001 , p. 57.

Protocolo de Montevidé, art. II. Disponivel em wwwmregovbr. Acessado em 22/05/2001. 
de pessoas físicas oriundas de um Estado-Parte prestando serviços no território de outro Estado-Parte também é modalidade indicada pelo Protocolo de Montevidéu.

Desse modo, é notória a influência do GATS nas normas estabelecidas pelo Protocolo de Montevidéu. Aliás, segundo Daniel Hargain, não poderia ser de outra maneira, já que os quatro Estados-Partes do MERCOSUL são também membros da $\mathrm{OMC}^{49}$. O predomínio das normas do GATS foi inevitável na confecção das normas mercosulinas.

Em contrapartida, o Protocolo de Montevidéu apresenta algumas inovações em relação ao GATS, demonstrando a evolução das normas e discussões visando o implemento do processo de integração.

A primeira delas está por conta do art. III $^{50}$, onde a Cláusula da Nação mais Favorecida é admitida sem restrições, ou seja, os Estados-Partes devem oferecer aos serviços e aos prestadores de serviços de qualquer outro Estado-Parte um tratamento não menos favorável do que aquele que oferece aos serviços similares e aos prestadores de serviços similares de qualquer outro Estado-Parte ou de terceiros países.

Em princípio, não se vislumbra a importância dessa cláusula, aplicável de maneira irrestrita. Contudo, para alguns setores de serviços, especialmente aqueles que dependem de outros serviços para o exercício regular de suas atividades, a inexistência de listas de exceções permite a concorrência entre prestadores de serviços nacionais e não-nacionais em igualdade de condições.

\footnotetext{
"HARGAIN, D. Marco Jurídico det Comercio Internacional de Servicios. In: Revista de Derecho del Mercosur, n." 4, Buenos Aires, 2001, p. 56-7.

5) Protocolo de Montevidéu, Artigo III. Tratamento da nação mais favorecida. 1- Com respeito às medidas compreendidas pelo presente Protocolo, cada Estado Parte outorgará inediata e incondicionalmente aos serviços e aos prestadores de serviços de qualquer outro Estado Parte um tratamento não menos favorável do que aquele que conceda aos serviços similares e aos prestadores de serviços similares de qualquer outro Estado Parte ou de terceiros paises. 2- As disposiçoes do presente Protocolo não setão interpretadas de forma a impedir que um Estado Parte outorgue ou conceda vantagens a países limítrofes, sejam ou näo Estados Partes, com of fim de facilitar intercâmbios limitados às zonas fronteiriças contiguas, de serviços que sejam produzidos e consumidos localmente. Disponivel em www.mre.gov.br. Acessado em $22 / 05 / 2001$
} 
Outra inovação é a prevista no art. $\mathrm{XX}^{51}$ que estabelece, de forma mais flexível, as hipóteses de suspensão e modificação dos compromissos específicos (basta notificar o Grupo Mercado Comum). Assim, caso um dos Estados-Partes queira suspender, paralisando temporariamente, ou modificar, alterando a forma e conteúdo, um ou mais compromissos específicos, basta que ele exponha e justifique as razões ao Grupo Mercado Comum.

Por outro lado, essa norma enseja o descumprimento dos compromissos assumidos pelos Estados Partes, que podem se utilizar dessa benesse sem real necessidade.

Finalmente, o art. XIX ${ }^{52}$ prevê rodadas anuais de negociação, com a finalidade de, no máximo em dez anos, estar completo o Programa de Liberalização do Comércio de Serviços do MERCOSUL. Nesse aspecto, a inovação está na previsão de rodadas anuais de negociação, demonstração do grande interesse dos Estados-Partes em ver consolidada a livre circulação de serviços, etapa de suma importância para o mercado comum.

É de se destacar, dentre as várias diretrizes que traça em relação aos scrviços e aos profis sionais prestadores de serviços no âmbito do MERCOSUL, o tratamento não menos favorável do que aquele outorgado aos serviços e aos prestadores de serviços nacionais. Portanto, segundo as palavras de Robson Zanetit ${ }^{53 .}$ o tratamento dispensado aos nãonacionais, deve ser, no mínimo, igual ao tratamento dispensado aos nacionais.

Isto porque essa igualdade de condições possibilita uma lealdade na concorrência para o exercicio das atividades, seja pelos nacionais, seja pelos não nacionais de um Estado-Parte, garantindo a liberalização do comércio de serviços, etapa de suma importância para o alcance do mercado comum.

\footnotetext{
5rotocolo de Montevidé, Artigo XX 1. Cada Estado Parte podrá, durante la implementación del Programa de Liberalización a que se vefiere la Parte III del presente Protocolo, modificar o suspender compromisos especificos includos en su Lista de compromisos específicos. Esta modificación o suspensión seráa aplicable sólo a partir de la fecha en que sea establecida y respetando el principio de no retroactividad para preservar los derechos adquiridos. 2. Cada Estado Parte recurrirá al presente régimen sólo en casos excepcionales, a condición de que cuando lo haga, notifique al Grupo Mercado Común y exponga ante el mismo los hechos, las razones y las justificaciones para tal modificacion o suspensión de compromisos. En tales casos, el Fstado Parte en cuestión celebrará consultas con el o los Estados Partes que se consideren afectados, para alcanzar un entendimiento consensuado sobre la medida espectica a ser aplicada y el plazo en que tendra vigencia. Disponível em www.mre.gov.br. Acessado en 22/05/2001

32. Protocolo de Montevidéu, Artigo XIX, 1. En cumplimiento de los objetrvos de presente Protocolo, los Estados Partes mantendrán sucesivas rondas de negociaciones a efectos de completar en un plazo máximo de diez anos, contados a partir de la extrada en vigor del presente Protocolo, el Programa de Liberalización del comercio de servicios del MERCOSUR. Las rondas de negociaciones se llevaran a cabo anualmente y tendrán como objetivo principal la incorporación progresiva de sectorés, subsectores, actividades y modos de prestación de servicios al Programa de Liberalización del Protocolo, así cono la reducción o la eliminación de los efectos desfavorables de las medidas sobre el comercio de servicios como forma de asegurar el acceso efectivo a los mercados. Este proceso tendrá por fia promover los intereses de todos los participantes, sobre la base de ventaiss mutuas, y conseguit un equilibrio global de derechos y obligaciones. Disponível em www.mre.gov.br. Acessado en 22/05/2001.

Z ZANETTI, R. O tratametato nacional entre os prestadores de serviços no MERCOSUL. Disponivel em http//www.lazaro.guimaraes nom.br/tratnachtm. Acessado em 22/05/2001. 
Esse tratamento nacional, disposto no artigo $5^{\mathrm{a}}, \S 1^{\mathrm{a}}$ do Protocolo de Montevidéu, estabelece a igualdade de direitos e obrigações entre os livre prestadores de serviços de um Estado-Parte, conferindo-lhes o acesso às atividades econômicas e o seu pleno exercício.

Contudo, a aplicação do tratamento nacional não tem sido suficiente para a plena implementação da liberdade de prestação de serviços, pois os Estados-Partes podem exigir de uma pessoa oriunda de outro Estado-Parte o cumprimento de certos requisitos para o exercício de uma atividade.

Integra igualmente o Protocolo uma lista de compromissos específicos através da qual cada Estado-Parte especificará os setores, os subsetores e as atividades aos quais explicitará termos, limitações e condições em matéria de acesso aos mercados e tratamento nacional.

Alguns setores necessitam de uma maior regulamentação, não podendo ser implementada a liberalização sem que sejam tomadas algumas cautelas, como forma de garantir a segurança nacional ${ }^{54}$.

O Protocolo visa, portanto, a exteriorização de um cenário interno relativo a cada Estado-Parte, o qual permita que se abrigue, em condiçóes de igualdade nacional, serviços e prestadores de serviços originários dos demais Estados integrantes do bloco.

Contudo, o que se constata é que os Estados Partes não gozam de uma situação confortável no que se refere à organização da prestação de serviços pelos nacionais em seu âmbito interno.

Havendo instabilidade no que se refere à prestação de serviços internamente, a implementação de um sistema que permita a efetiva circulação de serviços vê-se prejudicada. Impossível deferir-se tratamento não menos favorável ao estrangeiro, na medida em que o nacional não tem muito bem equacionado este tratamento.

Assim, como em vários outros aspectos, a adoção de uma normatividade supranacional mostra-se como alternativa bem-sucedida na implementação da livre circulação de serviços no MERCOSUL.

\section{Conclusão}

Independentemente das questões jurídicas acerca do tema prestação de serviços, para o Brasil, onde os serviços representam 57\% do produto interno bruto (PIB), a liberalização dos mercados mundiais significa o

\footnotetext{
3 Pode-se citar como exemplos os setores de serviços financeiros, serviços de transportes terresires e aquáticos e serviços de transpottes áreos.
} 
desenvolvimento das exportações brasileiras, que no ano de 1992 representavam $10 \%$ do total ${ }^{55}$.

A liberalização do comércio de serviços, desde que o país esteja atento à concorrência estrangeira, conseqüência natural da abertura de mercados, trará inúmeros benefícios na balança comercial brasileira. Estima-se que de 20 a $30 \%$ das riquezas do mundo circulam através dos serviços, sem considerar os serviços agregados ao comércio de bens.

Como forma de garantir direitos e deveres aos prestadores de serviços oriundos de outros Estados integrantes do bloco, os países do MERCOSUL devem estabelecer regras sociais mínimas. A proteção de direito reservado exclusivamente ao nacional contraria os princípios e objetivos do processo de integração do MERCOSUL.

Tendo em vista a infinidade de relações negociais que advêm do comércio de serviços, tem-se que o Protocolo de Montevidéu se constitui em norma que generaliza o instituto, sem definir, com precisão, suas particularidades, como, por exemplo, a definição de serviços, a questão do reconhecimento de diplomas e, principalmente, a questão da proteção do prestador de serviço que estiver fora de seu Estado-Parte.

Ou seja, qual é a segurança jurídica, considerando a proteção trabalhista e previdenciária, que o Estado-Parte oferece ao estrangeiro que estiver prestando serviços dentro do seu território? Qual a proteção legal que esse prestador de serviço oriundo de outro Estado-Parte terá em caso de acidente? E quanto ao aspecto da responsabilidade civil? São esses questionamentos que o Protocolo não responde.

Tais questionamentos deverão ser respondidos com a harmonização das legislações pertinentes dos Estados-partes integrantes do bloco. Contudo, os esforços nesse sentido têm-se mostrado escassos, haja vista que, após quase sete anos da aprovação do Protocolo pela Decisão 13/1997 do Conselho Mercado Comum, os Estados-partes sequer tomaram as medidas necessárias para a entrada em vigor do Protocolo. Conforme dito, o Protocolo de Montevidéu foi ratificado pelo Congresso Nacional Brasileiro, bem como pelo governo argentino. Os demais Estados-partes do MERCOSUL ainda não o fizeram, sendo que o Protocolo só entrará em vigor com a ratificação por todos os integrantes do bloco.

\footnotetext{
5 MERCADANTE, A.A. Acordo Geral sobre o Comercio de Servicos: aspectos juridicos. Th: CASELLA, P. B.; MERGADANTE, A. de A. (cootd); Guera comercial ou integragăo mundral pelo comércio? A OMC e o Brasil. Sä Panlo: LTr, 1998, p. 413. 
É importante salientar que o Protocolo de Montevidéu se constitui em um instrumento necessário para aproximar as legislações dos Estados-Partes, aumentando as convergências e permitindo o alcance do seu objetivo principal, que é a implementação do comércio de serviços entre os integrantes do bloco.

O Protocolo obtém êxito ao traçar uma agenda de negociação de compromissos específicos, estes regulados no artigo XIX, num prazo máximo de dez anos, para que o processo de liberalização progressiva seja implementado.

É imprescindivel que os Estados se organizem e equacionem a questão em seu âmbito interno, fato este do qual se parece estar um tanto distante, embora haja um explícito compromisso no sentido de se harmonizarem as respectivas legislações.

Não se pode considerar desenvolvimento econômico e comercial, tampouco integração, sem atentar-se para a importância do comércio de serviços. Daí a preocupação da $\mathrm{OMC}$ e dos blocos econômicos com a regulamentação desse tipo de atividade comercial e da liberdade de estabelecimento.

\section{BIBLIOGRAFIA}

ALVES, J. F. In: FIUZA, R. (coord.). NOVO CÓDIGO CIVIL COMENTADO. $1^{\circ}$ ed., $8^{\circ}$ tiragem. São Paulo: Saraiva, 2002.

ARGENTINA. CODIGO CIVIL DE LA NACION ARGENTINA. Disponível em http:/www.redetel.gov.ar/Normativa/Archivos $\% 20$ de $\% 20$ Normas/ CodigoCivil.htm. Acessado em 13/09/2001.

BATISTA, L. O. O Mercosul suas instituições e ordenamento jurídico. São Paulo: LTr, 1998.

BEVILÁQUA, C. Teoria das Obrigações, edição histórica, Rio de Janeiro: Editora Rio, 1977.

BOLÍVIA. CODIGO CIVIL DA BOLÍvIA. Disponível em http:/ www.cajpe.org.pe/rii/bases/legisla/bolivia/leyl1.HTM. Acessado em 13/09/ 2001.

BRASIL. Lei n.․․ 10.406, de 10/01/02, publicada no Diário Oficial da União em 11 de janeiro de 2002.

DE PLÁCIDO E SILVA. Vocábulo Jurídico. Rio de Janeiro: Forense, 1975, v. 1. Declaração Universal dos Direitos do Homem. Disponível em http:/ www.unhchr.ch/udhr/lang/por.htm. Acessado em 09/09/2002.

GATS. Disponivel em www.wto.org. Acessado cm 02/09/2002.

HARGAIN, D. Marco Jurídico del Comercio Internacional de Servicios. In: Revista de Derecho del Mercosur, n." 4, Buenos Aires, 2001.

LIPOVETZKY, J. C.; LIPOVETZKY, D. A. MERCOSUL estratégias pela integração: Mercado Comum do ou Zona de Livre Comércio? Análise e perspectivas do Tratado de Assunção. São Paulo: LTr.

LOPEZ, T. A. Da prestação de serviço. In: AZEVEDO, A. J. de (coord.). 
Comentários ao Código Civil: parte especial: das várias espécies de contrato, vol. 7. São Paulo: Saraiva, 2003.

MERCADANTE, A.A. Acordo Geral sobre o Comércio de Serviços: aspectos jurídicos. In: CASELLA, P. B.; MERCADANTE, A. de A. (coord.); Guerra comercial ou integração mundial pelo comércio? A OMC e o Brasil. São Paulo: LTr, 1998.

NORRIS, R. Contratos Coletivos Supranacionais de Trabalho e a Internacionalização das Relações Laborais no MERCOSUL. São Paulo: LTr, 1998. NOVO CODIGO CIVIL BRASILEIRO (Lei n.a 10.406, de 10/01/02), art. 594, $17^{\circ}$ ed., São Paulo: Saraiva, 2002.

PARAGUAI. CODIGO CIVIL DO PARAGUAI. Disponivel em Disponivel em. http:/ www.paraguaygobierno.gov.py/codigocivilestructurado.html. Acesso em 13/09/2001.

PARAGUAI. CODIGO CIVIL PARAGUAYO. Disponível em. http:// www.paraguaygobierno.gov.py/codigocivilestructurado.html. Acesso em 13/09/2001. PEDUZZI, M. C. I. A prestação de serviços. In: FRANCIULLI NETTO, D.; MENDES, G. F.; MARTINS FILHO, I. G. da. O Novo Código Civil: estudos em homenagem ao prof. Miguel Reale. São Paulo: LTr, 2003.

PERU. CODIGO CIVIL DO PERU. Disponível em http:/derecho.org/ comunidad/farnaas/leyes.htm. Acessado em. 13/09/2001.

PONTES DE MIRANDA, F. C. Tratado de Direito Privado, v. 47, São Paulo: Revista dos Tribunais, 1984.

PORTUGAL, H. H. de A. Atividade Empresarial \& Liberdade de Estabelecimento no MERCOSUL. Curitiba: Juruá, 2001.

PRONER, C. Comércio de Serviços. In: BARRAL. W. (org.). O Brasil e a $\mathrm{OMC}, 2^{\circ} \mathrm{ed}$, Curitiba: Juruá, 2002.

PROTOCOLO DE MONTEVIDÉU. Disponível em www.mre.gov.br. Acessado em 22/05/2001.

REVISTA DO MERCOSLIL apud PORTUGAL, H. H. de A. Atividade Empresarial \& Liberdade de Estabelecimento no MERCOSUL. Curitiba: Juruá, 2001. SALOMO, J. L. Aspectos dos Contratos de Prestação de Serviços. São Paulo: Juarez de Oliveira, 1999.

SALOMO, I. L. Contratos de Prestação de Serviços: manual prático e teórico. Säo Paulo: Juarez de Oliveira, 2001.

TAMAMES, R. La Unión Europea. Madrid: Alianza Editorial, 1994.

THORSTENSEN, V. OMC: as regras do comércio internacional e a rodada do milênio, $2^{\underline{Q}}$ ed. São Paulo: Aduaneiras, 2001.

TRATADO DE ASSUNÇÃO. Disponivel em http://www.mercosur.org.uy/ paginabienvenidaportugues.htm. Acessado em 17/07/2002.

VIEIRA, D. C. O Exercício da advocacia no Mercosul frente à livre circulação de serviços e trabalhadores. In: RODRIGUES, H. W. (org.). Solução de Controvérsias no Mercosul. Porto Alegre: Livraria do Advogado, 1997. ZANETTI, R. O tratamento nacional entre os prestadores de serviços no MERCOSUL. Disponível em http://www.lazaro.guimaraes.nom.br/ tratnac.htm. Acessado em 22/05/2001. 